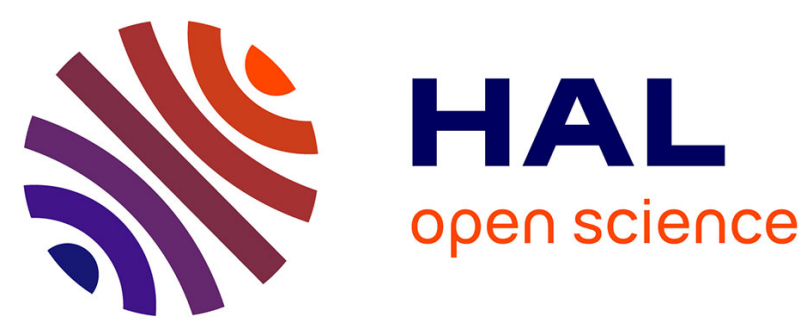

\title{
Maintenance of remission among patients with inflammatory bowel disease after vedolizumab discontinuation: a multicentre cohort study
}

Antoine Martin, Maria Nachury, Laurent Peyrin-Biroulet, Yoram Bouhnik, Stephane Nancey, Anne Bourrier, Mélanie Serrero, Mathurin Fumery, Anthony Buisson, David Laharie, et al.

\section{To cite this version:}

Antoine Martin, Maria Nachury, Laurent Peyrin-Biroulet, Yoram Bouhnik, Stephane Nancey, et al.. Maintenance of remission among patients with inflammatory bowel disease after vedolizumab discontinuation: a multicentre cohort study. Journal of Crohn's \& Colitis, 2020, 14 (7), pp.896-903. 10.1093/ecco-jcc/jjaa005 . hal-02442530

HAL Id: hal-02442530

https://hal-univ-rennes1.archives-ouvertes.fr/hal-02442530

Submitted on 17 Feb 2020

HAL is a multi-disciplinary open access archive for the deposit and dissemination of scientific research documents, whether they are published or not. The documents may come from teaching and research institutions in France or abroad, or from public or private research centers.
L'archive ouverte pluridisciplinaire HAL, est destinée au dépôt et à la diffusion de documents scientifiques de niveau recherche, publiés ou non, émanant des établissements d'enseignement et de recherche français ou étrangers, des laboratoires publics ou privés. 
Maintenance of remission among patients with inflammatory bowel disease after vedolizumab discontinuation: a multicentre cohort study

Authors: Antoine Martin ${ }^{1}$, Maria Nachury ${ }^{2}$, Laurent Peyrin-Biroulet ${ }^{3}$, Yoram Bouhnik ${ }^{4}$, Stephane Nancey ${ }^{5}$, Anne Bourrier ${ }^{6}$, Melanie Serrero ${ }^{7}$, Mathurin Fumery ${ }^{8}$, Anthony Buisson ${ }^{9}$, David Laharie ${ }^{10}$, Cyrielle Gilletta ${ }^{11}$, Jerome Filippi ${ }^{12}$, Matthieu Allez ${ }^{13}$, Guillaume Bouguen $^{14}$, Xavier Roblin ${ }^{15}$, Romain Altwegg ${ }^{16}$, Nina Dib ${ }^{17}$, Guillaume Pineton de Chambrun $^{16}$, Guillaume Savoye ${ }^{18}$, Franck Carbonnel ${ }^{19}$, Stephanie Viennot ${ }^{20}$, Aurelien Amiot ${ }^{1}$ on behalf of the GETAID-Vedo-STOP study group

1 Department of Gastroenterology, Henri Mondor Hospital, APHP, EC2M3-EA7375, Paris Est-Créteil Val de Marne University, Creteil, France.

2 Department of Gastroenterology, Huriez Hospital, Université of Lille, Lille, France.

3 INSERM U954 and Department of Gastroenterology, Université de Lorraine, Nancy, France

4 Department of Gastroenterology, IBD and Nutrition Support, Beaujon Hospital, University Paris 7 Denis Diderot, Clichy, France

5 Department of Gastroenterology, Hospices Civils de Lyon and University Claude Bernard Lyon 1, Pierre-Benite, France.

6 Department of Gastroenterology, Sorbonne Univeristé, INSERM, Centre de Recherche Saint-Antoine, CRSA, AP-HP, F-75012 Paris, France

7 Hôpital Nord, Centre d'investigation clinique Marseille Nord, Université Méditerranée, Marseille, France 
8 Department of Gastroenterology, Peritox UMRI-01, Amiens University Hospital, Amiens, France

9 Department of Hepato-Gastroenterology, University Hospital Estaing of Clermont-Ferrand, Université d'Auvergne, Clermont-Ferrand, France

10 Department of Hepato-Gastroenterology, University Hospital of Bordeaux, Hôpital HautLévêque, Bordeaux, France

11 Department of Gastroenterology, Toulouse University Hospital, Toulouse, France.

12 Department of Gastroenterology and Clinical Nutrition, Nice University Hospital, University of Nice Sophia-Antipolis, Nice, France

13 Department of Gastroenterology, Saint-Louis University Hospital, Paris, France.

14 Department of Gastroenterology, CHU Rennes and University of Rennes, INCERM, CIC1414, NUMECAN institute,F-35000 Rennes, France

15 Department of Gastroenterology, Saint-Etienne University Hospital, Saint-Etienne, France.

16 Department of Gastroenterology, Hôpital Saint-Eloi, University Hospital of Montpellier, Montpellier, France

17 Department of HepatoGastroenterology, Angers University Hospital, Angers, France.

18 Department of Gastroenterology, Rouen University Hospital, Rouen, France.

19 Department of Gastroenterology, Bicetre University Hospital, APHP, Université Paris Sud, le Kremlin Bicêtre, Paris, France

20 Department of Gastroenterology, Caen University Hospital, Caen, France 
All the members of the GETAID-Vedo-STOP study group are listed in the appendix.

\section{Abstract: 247 words}

Words count: 2747 words (excluding the abstract, references and appendix)

Please address correspondence and reprint requests to:

Professeur Aurelien AMIOT

Henri Mondor University Hospital - Universite Paris Est Creteil

51, Avenue du Marechal de Lattre de Tassigny CRETEIL F-94010 - FRANCE

Tel: +33-149812362

Fax: +33-149812352

E-mail: aurelien.amiot@hmn.aphp.fr

Keywords: Crohn's disease; ulcerative colitis; inflammatory bowel disease; vedolizumab.

Abbreviations: Crohn's disease: CD; ulcerative colitis: UC; inflammatory bowel disease: HBI: Harvey-Bradshaw index; CRP: C-reactive protein; PSC: primary sclerosing cholangitis.

\section{Conflicts of interest:}

Maria Nachury received lecture and consulting fees from Abbvie, Adacyte, Biogen, Boehringer-Ingelheim, Ferring, janssen, Mayoli Spindler, MSD, Pfizr and Takeda. 
Laurent Peyrin-Biroulet received consulting fees from Merck, Abbvie, Janssen, Genentech, Ferring, Norgine, Tillots, Vifor, Shire, Therakos, Pharmacosmos, Pilège, BMS, UCBPharma, Hospira, Celltrion, Takeda, Biogaran, Boerhinger-Ingelheim, Lilly, Pfizer, and HAC-Pharma. This author also received lecture fees from Merck, Abbvie, Takeda, Janssen Cilag, Ferring, Norgine, Tillots, Vifor, Therakos, HAC-Pharma, and Mitsubishi.

Yoram Bouhnik received lecture and consulting fees from Abbvie, Biogaran, BoehringerIngelheim, CTMA, Ferring, Gilead, Hospira, ICON, Inception IBD, Janssen, Lilly, Mayoli Spindler, Merck, MSD, Norgine, Pfizer, Robarts Clinical Trials, Roche, Sanofi, Shire, Takeda, UCB and Vifor Pharma. This author has also stock ownership of Inception IBD, San Diego, CA, USA.

Stephane Nancey received consulting fees from Merck, Abbvie, Takeda, Ferring, Norgine, Vifor Pharma, Novartis, Janssen Cilag, Hospira, Takeda and HAC Pharma.

Melanie Serrero received lecture fees from Abbvie, Ferring

Mathurin Fumery received lecture and consulting fees from Abbvie, MSD, Boehringer, Pfizer, Takeda, Janssen, Celgene, Tillotts, Janssen and Ferring.

Anthony Buisson received research funding from Pfizer, lecture fees from Abbvie, Ferring, Hospira, MSD, Janssen, Sanofi-Aventis, Takeda and Vifor Pharma and consulting fees from Abbvie, Biogen, Janssen, Pfizer and Takeda.

David Laharie has received consulting and lecture fees from AbbVie, Ferring, Janssen Cilag, MSD, Pfizer, and Takeda.

Jerome Filippi received lecture and consulting fees from Abbvie, Astellas pharma, Covidien, Ferring, Jansen, MSD, Pfizer, Takeda. 
Matthieu Allez received honoraria from Novo Nordisk, MSD, Abbvie, Ferring, Genentech, Janssen, Pfizer, GSK, Hospira, UCB, Novartis, Takeda, Mayolo-Spindler.

Guillaume Bouguen received lecture fees from Abbvie, Ferring, MSD, Takeda and Pfizer and consultant fees from Takeda, Janssen.

Xavier Roblin reported a relationship with MSD, Abbvie, Amgen, Sandoz, Pfizer, Takeda and Janssen.

Guillaume Pineton de Chambrun received lecture fees from Pfizer, MSD, AbbVie, Takeda, and Ferring; and consulting fees from Takeda, Tillots Pharma, and Janssen.

Guillaume Savoye received lecture fees from Vifor Pharma, Takeda, Pfizer, HAC Pharma, Abbvie, MSD, and Ferring France. This author has also received travel accommodations from Ferring, Abbvie, and MSD France as well as a research grant from Ferring.

Stephanie Viennot received consulting fees from Abbvie, MSD, Takeda, Vifor Pharma and Ferring.

Aurelien Amiot received consulting lecture and consulting fees from Abbvie, Hospira, Takeda, Gilead, Adacyte, Tillotts, and Biocodex as well as lecture fees and travel accommodations from Abbvie, Janssen, Biocodex, Hospira, Ferring, Takeda and MSD. This author has also received advisory board fees from Gilead, Takeda and Abbvie.

No conflicts of interest are claimed by the remaining authors.

Study funding: None.

\section{Author contributions:}

Conception and design of the study: AM, ABu, JF, SN, GPdC, PS, MF, LPB, AA 
Generation, Collection, Assembly, Analysis and/or Interpretation of data: AM, MA, LPB, YB, SN, ABo, MS, MF, ABu, DL, CG, JF, MA, GB, XR, RA, ND, GPdC, GS, FC, SV, AA

Drafting or revision of the manuscript: $\mathrm{AM}, \mathrm{MA}, \mathrm{LPB}, \mathrm{YB}, \mathrm{SN}, \mathrm{ABo}, \mathrm{MS}, \mathrm{MF}, \mathrm{ABu}, \mathrm{DL}$, CG, JF, MA, GB, XR, RA, ND, GPdC, GS, FC, SV, AA

Approval of the final version of the manuscript: AM, MA, LPB, YB, SN, ABo, MS, MF, ABu, DL, CG, JF, MA, GB, XR, RA, ND, GPdC, GS, FC, SV, AA 


\section{ABSTRACT}

Introduction: It is unclear whether vedolizumab therapy can be discontinued in patients with inflammatory bowel disease (IBD) after achieving steroid-free clinical remission.

Aim: To assess the risk of relapse after vedolizumab therapy was discontinued.

Patients and Methods: Retrospective observational study, collecting data from 21 tertiary centres affiliated with the GETAID from January 2017 to April 2019. Consecutive patients with IBD who were in steroid-free clinical remission for at least three months and were treated with vedolizumab for at least six months were included at the time of vedolizumab discontinuation.

Results: Ninety-five patients (58 with Crohn's disease) discontinued vedolizumab after a median duration of therapy of 17.5 [10.6-25.4] months. After a median follow-up period of $11.2(5.8-17.7)$ months, $61(64 \%)$ patients experienced disease relapse. The probabilities of relapse-free survival were $83 \%, 59 \%$ and $36 \%$ at 6,12 and 18 months, respectively. According to the multivariate analysis, a CRP level less than $5 \mathrm{mg} / \mathrm{L}$ at vedolizumab discontinuation $(\mathrm{HR}=0.56,95 \% \mathrm{CI}[0.33-0.95], \mathrm{p}=0.03)$ and discontinuation due to patients' elective choice $(\mathrm{HR}=0.41,95 \% \mathrm{CI}[0.21-0.80], \mathrm{p}=0.009)$ were significantly associated with a lower risk of relapse. Re-treatment with vedolizumab was noted in 24 patients and provided steroid-free clinical remission in $71 \%$ and $62.5 \%$ at week 14 and after a median follow-up of 11.0 [5.4-13.3] months, respectively, without any infusion reactions.

Conclusion: In this retrospective study, two-thirds of patients with IBD treated with vedolizumab experienced relapse within the first year after vedolizumab discontinuation. Retreatment with vedolizumab was effective in two-thirds of patients. 


\section{Introduction}

Inflammatory bowel diseases (IBD), including Crohn's disease (CD) and ulcerative colitis (UC), are chronic and disabling diseases characterized by a sequence of flares and remission $^{1,2}$. The advent of biological agents has changed the way we treat patients with IBD, resulting in dramatic improvements in the goals of treatment and the benefits to patients ${ }^{3,4}$. However, once patients achieve stable steroid-free clinical remission, there is no clear recommendation regarding treatment discontinuation ${ }^{5}$. Cessation of biological agents may be considered due to long-term safety issues, economic burden and the desire of patients to discontinue medication. However, concerns about the discontinuation of biological agents rely on the risk of relapse, impairment of previous efficacy after the drug has been restarted and adverse events at re-treatment.

In a prospective multicentre cohort study, Louis et al. provided the first experience of infliximab discontinuation in patients with $\mathrm{CD}$ who were in prolonged remission longer than 6 months $^{6}$. After one year, the rate of relapse was $44 \%$. Recently, a large retrospective study that included more than 1000 patients showed a yearly risk of relapse after adalimumab and infliximab discontinuation of $18 \%$ per patient-year ${ }^{7}$. In this study, predictors of relapse were younger age, adalimumab vs. infliximab, discontinuation due to safety issues and/or patients' elective choice and the absence of a maintenance immunomodulator after anti-TNF discontinuation.

Vedolizumab is an anti- $\alpha 4 \beta 7$ integrin monoclonal antibody that inhibits the recruitment of inflammatory cells in the intestine ${ }^{8}$. The efficacy and safety of vedolizumab have been demonstrated in patients with $\mathrm{UC}$ and $\mathrm{CD}$ in clinical trials and observational studies $^{9-14}$. There are currently no data on vedolizumab discontinuation in patients in clinical remission. 
The aim of the present study was to determine the risk of relapse after vedolizumab discontinuation and the effectiveness of re-treatment with vedolizumab.

\section{Patients and Methods}

\section{Study population}

The present study was an observational, multicentre, retrospective cohort study conducted at 21 French tertiary centres affiliated with the Groupe d'Etudes Thérapeutiques des Affections Inflammatoires Digestives (GETAID).

The study population comprised consecutive patients with IBDs, either CD or UC, who had been treated with vedolizumab for at least six months and who discontinued vedolizumab after at least three months of stable steroid-free clinical remission, from January 2017 to April $2019^{5-7}$. Reasons for vedolizumab discontinuation were either patient's elective choice, pregnancy, safety issues or reimbursement issues. Patients who had been treated with vedolizumab for less than six months, those with evidence of disease activity or oral steroids during the last three months before discontinuation and those who initiated any new IBD treatment after vedolizumab discontinuation were excluded.

The protocol was approved by an ethics committee (CCTIRS $\left.\mathrm{N}^{\circ} 15.403\right)$. All authors had access to the study data and reviewed and approved the final manuscript.

\section{Data collection}

The inclusion date corresponds to the date of the last infusion of vedolizumab. Baseline patient demographic, clinical and endoscopic characteristics were collected from medical records and included age, sex, smoking habits, extraintestinal manifestation, familial history 
of IBD, history of medical and surgical treatment of IBD, date of diagnosis, and behaviour of disease according to the Montreal classification.

Disease activity and safety were assessed at various time points: at the first infusion of vedolizumab, at inclusion, every 6 months until 24 months after the discontinuation of vedolizumab and at the end of follow-up. At each time point, clinical activity was assessed using the Harvey Bradshaw index (HBI) for patients with $\mathrm{CD}$ and the partial Mayo Clinic score for patients with UC. Biological activity was assessed using haemoglobin, CRP, albuminemia and faecal calprotectin. Endoscopic activity was assessed using the Mayo Clinic endoscopic subscore and ulcerative colitis endoscopic index of severity (UCEIS) for patients with UC. Endoscopic assessment of CD activity was not mandatory and was at the investigator's discretion. Severe adverse events were defined as the occurrence of treatment interruption, hospitalization, disability, persistent damage, colectomy or death.

The concomitant use of 5ASA and/or immunomodulators for IBD at the time of discontinuation of vedolizumab therapy was allowed according to the investigator's decision and was recorded at the time of discontinuation of vedolizumab therapy and thereafter until the end of follow-up.

Patients experiencing relapse were assessed for response and safety at week 14 after vedolizumab was reintroduced or after another IBD treatment was started and at the end of the follow-up period.

\section{Outcome measures}

Clinical remission was defined as an $\mathrm{HBI}<4$ for patients with $\mathrm{CD}$ and a partial Mayo Clinic score $<3$ for patients with UC with a combined stool frequency and rectal bleeding subscore of 1 or less for UC. Relapse was defined by active disease according to an HBI $\geq 4$ 
and the introduction of any specific systemic IBD treatment, IBD-related hospitalization and/or surgery. The effectiveness and safety of re-treatment with vedolizumab were also assessed.

Mucosal healing was defined as the absence of any ulcer for patients with CD and as a Mayo Clinic endoscopic subscore of 0 or 1 for patients with UC.

Severe adverse events were defined as the occurrence of treatment interruption, hospitalization, disability, persistent damage, colectomy or death.

\section{Statistical analysis}

Quantitative data are expressed as the mean and standard deviation (SD) or median [interquartile range], whereas qualitative data are expressed as a number (\%). Hazard ratios (HRs) are given with their 95\% confidence intervals (CIs). Relapse-free survival was studied using the Kaplan-Meier method. Patients who restarted vedolizumab without any evidence of clinically active disease were censored at the time of vedolizumab reintroduction. To identify predictors of relapse, the survival distributions were studied using the log-rank test for the univariate analysis and then using Cox proportional hazard models for the multivariate analysis. Furthermore, p-values less than 0.10 in the univariate analysis were considered significant and allowed for inclusion in the multivariate analysis, whereas p-values less than 0.05 were considered significant for other analyses. All of the statistical evaluations were performed using SPSS statistical software (SPSS Inc., v23, Chicago, IL, USA). 


\section{RESULTS}

\section{Characteristics of the study population}

Ninety-five patients (24 males; median age: 32.5 [IQR 27.3-42.4] years) from 21 GETAID centres who discontinued vedolizumab therapy from January 2017 to April 2019 were included. The baseline demographic and clinical characteristics are presented in Table 1. Briefly, $58(61 \%)$ patients had CD with a mean $\mathrm{HBI}$ of $1.7 \pm 1.4$ at inclusion, and $37(39 \%)$ had UC with a mean partial Mayo Clinic score of $0.7 \pm 1.1$ at inclusion. At baseline, mucosal healing was observed in 22/38 (58\%) patients with CD and 19/26 (73\%) patients with UC.

At baseline, the median duration of vedolizumab therapy was 14.5 [8.2-21.5] months. Patients were treated either every 8 weeks in $68(72 \%)$ patients or every four weeks in 27 (28\%). The reasons for vedolizumab discontinuation were pregnancy in 37 (39\%), safety issues in $26(28 \%)$, patients' elective choice in $24(25 \%)$ and reimbursement issues in $8(8 \%)$. At baseline, only 7 (7\%) patients were treated concomitantly with immunosuppressants and $21(22 \%)$ with aminosalicylates.

\section{Clinical relapse}

After a median follow-up of 11.2 (5.8-17.2) months, 61 (64\%) patients experienced relapse. The median time to relapse was 13.2 (10.8-15.6) months. The probabilities of relapse-free survival were $83 \%, 59 \%$ and $36 \%$ at 6,12 and 18 months, respectively.

Based on the univariate analysis, a CRP level $<5 \mathrm{mg} / \mathrm{L}$ at inclusion, vedolizumab discontinuation as an elective choice, an HBI or a partial Mayo Clinic score at the time of vedolizumab discontinuation $\leq 1$, mucosal healing and a leukocyte count $<8000 / \mathrm{mm}^{3}$ were associated with a lower risk of relapse, whereas reimbursement issues and steroids at the time of vedolizumab introduction were associated with a higher risk of relapse. No difference was 
found between patients with CD and UC in relapse-free survival ( $p=0.40$, Figure 2). Based on the multivariate analysis, patients with a CRP level $<5$ at the time of vedolizumab discontinuation $(\mathrm{HR}=0.56,95 \% \mathrm{CI}[0.33-0.95], \mathrm{p}=0.03)$ and those who discontinued vedolizumab as an elective choice $(\mathrm{HR}=0.41,95 \% \mathrm{CI}[0.21-0.80], \mathrm{p}=0.009)$ were less likely to experience relapse (Figure 2).

\section{Outcome of vedolizumab re-treatment}

Among the 61 patients who experienced a relapse, vedolizumab was re-introduced in 24 (39\%). Re-treatment consisted of a standard induction regimen with three 300-mg infusions at weeks 0,2 and 6 in all cases. The rate of steroid-free clinical remission after vedolizumab re-treatment at week 14 was $71 \%$. After a median follow-up of 11.0 [5.4-13.3] months after vedolizumab re-treatment, $15(62.5 \%)$ patients were still in clinical remission on vedolizumab therapy. No infusion reaction was noted after vedolizumab re-treatment during the induction phase and thereafter.

Among patients who relapsed, $37(60.7 \%)$ were not re-treated with vedolizumab. Rescue therapy included ustekinumab $(n=15)$, surgery $(n=7)$, prolonged steroids $(n=7)$, additional anti-TNF $(n=3), 5-\operatorname{ASA}(n=3)$ cyclophosphamide $(n=1)$ and tofacitinib $(n=1)$. Prolonged steroid therapy was chosen in seven patients due to the patients' choice $(n=3)$, pregnancy $(n=2)$, multiple sclerosis $(n=1)$ and concomitant breast cancer $(n=1)$.

\section{DISCUSSION}

Whether a drug should be continued when clinical remission has been achieved is highly controversial. Indeed, the likelihood of relapse after discontinuing treatment may be as high as $30-40 \%$ in patients treated with anti-TNF, and the re-introduction of the same 
treatment is often but not always as efficient as before ${ }^{5}$. On the other hand, socio-economic issues, the cumulative risk of serious adverse events over time and other circumstances, including pregnancy and the will of patients, promote discontinuation ${ }^{15}$. Herein, we provide the first data on vedolizumab discontinuation in patients who achieved steroid-free clinical remission. Clinical relapse occurred in $64 \%$ of patients after 18 months of discontinuation. Clinical relapse was even more frequent when discontinuation occurred in patients with a CRP level $>5 \mathrm{mg} / \mathrm{L}$ and when discontinuation occurred as an incidental event rather than as an elective choice. In the case of vedolizumab reintroduction, steroid-free clinical remission was achieved in two-thirds of patients at week 14 and during the 11-month follow-up period.

Evidence from clinical trials and observational studies has identified differences in the modes of action between vedolizumab and anti-TNF agents ${ }^{14,16-18}$. Although vedolizumab has been used frequently after anti-TNF failure, it has often been characterized by a slow action during the induction phase and has stable effectiveness over time. Cycling therapy has been proposed in IBD to prevent incidental adverse events ${ }^{2,15}$. In patients who discontinued anti-TNF, mostly infliximab, after a period of remission, the risk of relapse was $40 \%$ at 12 months for patients with CD and $28 \%$ for those with UC, according to a meta-analysis of 27 studies $^{19}$. In the present series, we provide the first data of patients discontinuing vedolizumab after achieving steroid-free clinical remission. After a follow-up period of 11.2 months, the risk of relapse was $59 \%$ at 12 months. A direct comparison between anti-TNF and vedolizumab after treatment discontinuation is questionable. Indeed, most of the patients in the present series had been previously treated with immunomodulators $(87 \%$ of the patients) and anti-TNF (91\%), which was not the case for data from patients discontinuing anti-TNF. Further prospective studies should assess the risk of relapse in patients with vedolizumab to improve decision making when discontinuation is discussed with patients. 
Little is known about the optimal duration of therapy with a biological agent for patients with IBD before discontinuation may be considered. In patients discontinuing thiopurine, the risk of relapse was reduced when patients were treated for more than four years $^{20}$. Indeed, although patients are deemed to relapse due to genetic predisposition, environmental factors, the gut microbiome and underlying impairments of intestinal immunity, a longer duration of remission may be associated with a more profound restoration of intestinal immunity that could be beneficial to better maintain remission after discontinuing a drug${ }^{21,22}$. Evidence that a longer duration of anti-TNF therapy until its discontinuation favours a lower risk of relapse has not yet been demonstrated. This concept has been supported by early experience with infliximab with a poorer long-term outcome in patients treated with only three infliximab induction infusions ${ }^{23}$. The majority of the study assessing the risk of relapse after anti-TNF discontinuation included patients treated for at least 2 years with anti-TNF. In a recent multicentre observational study that included 1,055 patients with IBD, Casanova et al showed that a top-down strategy with early discontinuation of anti-TNF was associated with a lower risk of relapse than elective discontinuation or discontinuation for safety issues ${ }^{7}$. In our study, elective discontinuation (vs. safety issues, pregnancy or reimbursement issues) was associated with a lower risk of relapse but not a longer duration of vedolizumab therapy. The fact that very few patients had taken concomitant immunomodulators may be an explanation, but the majority of patients had been treated previously with at least one immunomodulator and had experience with failure or intolerance to the drug. It is not also conceivable that elective discontinuation reflects a more deep remission compared with unscheduled events such as pregnancy, safety issues or reimbursement issues.

The combination of steroid-free clinical remission and mucosal healing is now recommended in clinical trials and in daily practice in a treat-to-target manner ${ }^{4,24}$. Indeed, the 
achievement of mucosal healing was associated with a reduced risk of relapse, fewer hospitalizations and fewer surgeries in mostly retrospective studies ${ }^{1,2}$. In the CALM study, Colombel et al demonstrated with a prospective trial the benefits of targeting mucosal healing assessed with faecal calprotectin compared with a symptom-based strategy ${ }^{24}$. In the present study, patients with mucosal healing had a lower probability of relapse after vedolizumab discontinuation according to the univariate analysis $(22 \%$ vs $39 \%$ at 12 months; $\mathrm{OR}=0.57$ [0.25-0.89], $\mathrm{p}=0.002)$. The presence of mucosal healing is a major issue when considering the discontinuation of a biologic, even if its predictive value was not confirmed in our multivariate, probably due to a lack of endoscopic assessment before discontinuation in onethird of patients (31 out of 95). However, we showed evidence that residual systemic inflammation characterized by a CRL level $>5 \mathrm{mg} / \mathrm{L}$ at the time of discontinuation was a predictor of relapse according to the multivariate analysis.

In the present study, 24 out of 61 patients who experienced clinical relapse were retreated with vedolizumab with a 14 -week steroid-free clinical remission rate of $71 \%$. These results are in line with similar experiences with thiopurine and anti-TNF. Indeed, two studies have reported similarly successful re-introduction of thiopurines after discontinuation in $85 \%$ of patients with $\mathrm{IBD}^{25,26}$. A recent meta-analysis reported that re-treatment with anti-TNF after discontinuation induced clinical remission in $80 \%$ of patients with IBD $^{19}$. A high proportion of patients $(60.7 \%)$ were not re-treated with vedolizumab after relapse. Some were referred for surgery $(n=7)$ because of bowel complications at the time of relapse, and seven decided to remain on steroids $(n=7)$ for various reasons (own decision, contraindication to any anti-TNF or patient's decision). Some were treated with other biological agents, mostly ustekinumab, for reasons we could only extrapolate, safety issues leading to discontinuation, benefits of 8-12 weekly subcutaneous injections compared to 4-8 weekly intravenous infusions and the lack of data considering vedolizumab re-introduction. 
We acknowledge several limitations of this study, including its retrospective design, the lack of a mucosal healing assessment or faecal calprotectin measurement, the absence of therapeutic drug monitoring at the time of vedolizumab discontinuation and the absence of a detailed follow-up protocol. However, this study also has several strengths. First, we provide original data in the field of discontinuing vedolizumab after achieving steroid-free clinical remission. Second, the sample size for each patient population is considered clinically relevant. Third, patients were recruited in GETAID centres allowing high experience and compliance to ECCO guidelines for the management of patients with IBD.

In conclusion, two-thirds of patients experienced clinical relapse after vedolizumab discontinuation at the time of steroid-free clinical remission. Further studies are warranted to confirm our data and determine whether longer durations of vedolizumab therapy and deep remission could afford the opportunity for this strategy. Overall, our findings are not in favour of vedolizumab discontinuation with the exception of indisputable reasons such as pregnancy or safety issues. 


\section{FIGURE LEGENDS}

Figure 1: Kaplan-Meier relapse-free survival curve after vedolizumab therapy was discontinued in 95 patients with inflammatory bowel disease with steroid-free clinical remission for at least three months and vedolizumab therapy for at least six months

Figure 2: Kaplan-Meier relapse-free survival curve after vedolizumab therapy was discontinued according to the CRP level at the time of discontinuation (Panel A) and reason for discontinuation (Panel B)

\section{TABLE LEGENDS}

Table 1: Demographics, disease characteristics and medication histories of 95 patients with inflammatory bowel disease with steroid-free clinical remission for at least three months and vedolizumab therapy for at least six months, at the time of vedolizumab discontinuation

Table 2: The predictors associated with clinical relapse after discontinuation of vedolizumab in 95 patients with inflammatory bowel disease in steroid-free clinical remission for at least three months, treated with vedolizumab therapy for at least six months. 


\section{REFERENCES}

1. Ungaro R., Mehandru S., Allen PB., Peyrin-Biroulet L., Colombel J-F. Ulcerative colitis. Lancet Lond Engl 2017;389(10080):1756-70. Doi: 10.1016/S0140-6736(16)32126-2.

2. Torres J., Mehandru S., Colombel J-F., Peyrin-Biroulet L. Crohn's disease. Lancet Lond Engl 2017;389(10080):1741-55. Doi: 10.1016/S0140-6736(16)31711-1.

3. Bouguen G., Levesque BG., Feagan BG., Kavanaugh A., Peyrin-Biroulet L., Colombel JF., et al. Treat to target: a proposed new paradigm for the management of Crohnés disease. Clin Gastroenterol Hepatol 2015;13(6):1042-50.

4. Peyrin-Biroulet L., Sandborn W., Sands BE., Reinisch W., Bemelman W., Bryant RV., et al. Selecting Therapeutic Targets in Inflammatory Bowel Disease (STRIDE): Determining Therapeutic Goals for Treat-to-Target. Am J Gastroenterol 2015;110(9):132438. Doi: 10.1038/ajg.2015.233.

5. Doherty G., Katsanos KH., Burisch J., Allez M., Papamichael K., Stallmach A., et al. European Crohn's and Colitis Organisation Topical Review on Treatment Withdrawal ['Exit Strategies'] in Inflammatory Bowel Disease. J Crohns Colitis 2018;12(1):17-31. Doi: 10.1093/ecco-jcc/jjx 101 .

6. Louis E., Mary JY., Vernier-Massouille G., Grimaud JC., Bouhnik Y., Laharie D., et al. Maintenance of remission among patients with Crohn's disease on antimetabolite therapy after infliximab therapy is stopped. Gastroenterology 2012;142(1):63-70 e5; quiz e31.

7. Casanova MJ., Chaparro M., García-Sánchez V., Nantes O., Leo E., Rojas-Feria M., et al. Evolution After Anti-TNF Discontinuation in Patients With Inflammatory Bowel Disease: A Multicenter Long-Term Follow-Up Study. Am J Gastroenterol 2017;112(1):12031. Doi: 10.1038/ajg.2016.569. 
8. Lobatón T., Vermeire S., Van Assche G., Rutgeerts P. Review article: anti-adhesion therapies for inflammatory bowel disease. Aliment Pharmacol Ther 2014;39(6):579-94. Doi: 10.1111/apt.12639.

9. Sandborn WJ., Feagan BG., Rutgeerts P., Hanauer S., Colombel J-F., Sands BE., et al. Vedolizumab as induction and maintenance therapy for Crohn's disease. N Engl J Med 2013;369(8):711-21. Doi: 10.1056/NEJMoa1215739.

10. Feagan BG., Rutgeerts P., Sands BE., Hanauer S., Colombel JF., Sandborn WJ., et al. Vedolizumab as induction and maintenance therapy for ulcerative colitis. $N$ Engl $J$ Med 2013;369(8):699-710. Doi: 10.1056/NEJMoa1215734.

11. Sands BE., Feagan BG., Rutgeerts P., Colombel J-F., Sandborn WJ., Sy R., et al. Effects of vedolizumab induction therapy for patients with Crohn's disease in whom tumor necrosis factor antagonist treatment failed. Gastroenterology 2014;147(3):618-627.e3. Doi: 10.1053/j.gastro.2014.05.008.

12. Chaparro M., Garre A., Ricart E., Iborra M., Mesonero F., Vera I., et al. Short and long-term effectiveness and safety of vedolizumab in inflammatory bowel disease: results from the ENEIDA registry. Aliment Pharmacol Ther 2018;48(8):839-51. Doi: 10.1111/apt.14930.

13. Schreiber S., Dignass A., Peyrin-Biroulet L., Hather G., Demuth D., Mosli M., et al. Systematic review with meta-analysis: real-world effectiveness and safety of vedolizumab in patients with inflammatory bowel disease. J Gastroenterol 2018;53(9):1048-64. Doi: 10.1007/s00535-018-1480-0.

14. Amiot A., Serrero M., Peyrin-Biroulet L., Filippi J., Pariente B., Roblin X., et al. Three-year effectiveness and safety of vedolizumab therapy for inflammatory bowel disease: 
a prospective multi-centre cohort study. Aliment Pharmacol Ther 2019;50(1):40-53. Doi: 10.1111/apt.15294.

15. Louis E. Stopping Biologics in IBD-What Is the Evidence? Inflamm Bowel Dis 2018;24(4):725-31. Doi: 10.1093/ibd/izx098.

16. Engel T., Ungar B., Yung DE., Ben-Horin S., Eliakim R., Kopylov U. Vedolizumab in IBD-Lessons From Real-world Experience; A Systematic Review and Pooled Analysis. $J$ Crohns Colitis 2018;12(2):245-57. Doi: 10.1093/ecco-jcc/jjx143.

17. Amiot A., Grimaud J-C., Peyrin-Biroulet L., Filippi J., Pariente B., Roblin X., et al. Effectiveness and Safety of Vedolizumab Induction Therapy for Patients With Inflammatory Bowel Disease. Clin Gastroenterol Hepatol Off Clin Pract J Am Gastroenterol Assoc 2016;14(11):1593-1601.e2. Doi: 10.1016/j.cgh.2016.02.016.

18. Amiot A., Serrero M., Peyrin-Biroulet L., Filippi J., Pariente B., Roblin X., et al. Oneyear effectiveness and safety of vedolizumab therapy for inflammatory bowel disease: a prospective multicenter cohort study. Aliment Pharmacol Ther 2017:in press.

19. Gisbert JP., Marin AC., Chaparro M. The risk of relapse after anti-TNF discontinuation in inflammatory bowel disease: systematic review and meta-analysis. Am $J$ Gastroenterol n.d.;111(5):632-47.

20. Bouhnik Y., Lémann M., Mary JY., Scemama G., Taï R., Matuchansky C., et al. Long-term follow-up of patients with Crohn's disease treated with azathioprine or 6mercaptopurine. Lancet Lond Engl 1996;347(8996):215-9. Doi: 10.1016/s01406736(96)90402-x.

21. Sorrentino D., Nash P., Viladomiu M., Hontecillas R., Bassaganya-Riera J. Stopping anti-TNF agents in patients with Crohn's disease in remission: is it a feasible long-term 
strategy? Inflamm Bowel Dis 2014;20(4):757-66. Doi: 10.1097/01.MIB.0000442680.47427.bf.

22. Gisbert JP., Marín AC., Chaparro M. Systematic review: factors associated with relapse of inflammatory bowel disease after discontinuation of anti-TNF therapy. Aliment Pharmacol Ther 2015;42(4):391-405. Doi: 10.1111/apt.13276.

23. Schnitzler F., Fidder H., Ferrante M., Noman M., Arijs I., Van Assche G., et al. Longterm outcome of treatment with infliximab in 614 patients with Crohn's disease: results from a single-centre cohort. Gut 2009;58(4):492-500. Doi: 10.1136/gut.2008.155812.

24. Colombel J-F., Panaccione R., Bossuyt P., Lukas M., Baert F., Vaňásek T., et al. Effect of tight control management on Crohn's disease (CALM): a multicentre, randomised, controlled phase 3 trial. Lancet Lond Engl 2018;390(10114):2779-89. Doi: 10.1016/S01406736(17)32641-7.

25. Kennedy NA., Warner B., Johnston EL., Flanders L., Hendy P., Ding NS., et al. Relapse after withdrawal from anti-TNF therapy for inflammatory bowel disease: an observational study, plus systematic review and meta-analysis. Aliment Pharmacol Ther 2016;43(8):910-23. Doi: 10.1111/apt.13547.

26. Treton X., Bouhnik Y., Mary J-Y., Colombel J-F., Duclos B., Soule J-C., et al. Azathioprine withdrawal in patients with Crohn's disease maintained on prolonged remission: a high risk of relapse. Clin Gastroenterol Hepatol Off Clin Pract J Am Gastroenterol Assoc 2009;7(1):80-5. Doi: 10.1016/j.cgh.2008.08.028. 


\section{APPENDIX: Members of the GETAID-Vedo-STOP study group}

Aurélien Amiot, Antoine Martin, Charlotte Gagnière. Department of Gastroenterology, Henri Mondor Hospital, APHP, EC2M3-EA7375, Paris Est-Créteil Val de Marne University, Creteil, France

Maria Nachury, Benjamin Pariente, Pauline Wils. Department of Gastroenterology, Huriez Hospital, Université of Lille, Lille, France.

Laurent Peyrin-Biroulet, Camille Zallot. INSERM U954 and Department of Gastroenterology, Université de Lorraine, Nancy, France

Yoram Bouhnik, Xavier Treton, Carmen Stefanescu. Department of Gastroenterology, IBD and Nutrition Support, Beaujon Hospital, University Paris 7 Denis Diderot, Clichy, France

Stephane Nancey, Gilles Boschetti. Department of Gastroenterology, Hospices Civils de Lyon and University Claude Bernard Lyon 1, Pierre-Benite, France.

Philippe Seksik, Laurent Beaugerie, Julien Kirchgesner, Anne Bourrier, Harry Sokol. Department of Gastroenterology, AP-HP, Hôpital Saint-Antoine, F-75012, ERL 1057 INSERM/UMRS 7203, UPMC Université Paris 6, Paris, France

Melanie Serrero. Hôpital Nord, Centre d'investigation clinique Marseille Nord, Université Méditerranée, Marseille, France

Mathurin Fumery, Clara Yzet, Franck Brazier. Department of Gastroenterology, Amiens University Hospital, Amiens, France

David Laharie, Pauline Rivière, Florian Poullenot. Department of Hepato-Gastroenterology, University Hospital of Bordeaux, Hôpital Haut-Lévêque, Bordeaux, France 
Anthony Buisson. Department of Gastroenterology, University of Clermont Ferrand, Clermont-Ferrand, France

Cyrielle Gilletta. Department of Gastroenterology, Toulouse University Hospital, Toulouse, France.

Jérôme Filippi, Xavier Hebuterne. Department of Gastroenterology and Clinical Nutrition, Nice University Hospital, University of Nice Sophia-Antipolis, Nice, France

Matthieu Allez, Jean-Marc Gornet. Department of Gastroenterology, Saint-Louis University Hospital, Paris, France

Guillaume Bouguen, Laurent Siproudhis. Department of Gastroenterology, Pontchaillou Hospital and Rennes University, Rennes, France

Xavier Roblin. Department of Gastroenterology, Saint-Etienne University Hospital, SaintEtienne, France.

Romain Altwegg, Guillaume Pineton de Chambrun. Department of Gastroenterology, Hôpital Saint-Eloi, University Hospital of Montpellier, Montpellier, France

Nina Dib. Department of Gastroenterology, Angers University Hospital, Angers, France.

Guillaume Savoye. Department of Gastroenterology, Rouen University Hospital, Rouen, France

Franck Carbonnel, Antoine Meyer. Department of Gastroenterology, Bicetre University Hospital, Le Kremlin-Bicetre, France

Stephanie Viennot, Guillaume Lebaut. Department of Gastroenterology, Caen University Hospital, Caen, France 
Table 1: Demographics, disease characteristics and medication histories of 95 patients with inflammatory bowel disease with steroid-free clinical remission for at least three months and vedolizumab therapy for at least six months, at the time of vedolizumab discontinuation

\begin{tabular}{|c|c|c|}
\hline Characteristic & $\begin{array}{l}\text { Crohn's disease } \\
\qquad(\mathbf{n}=\mathbf{5 8})\end{array}$ & $\begin{array}{l}\text { Ulcerative colitis } \\
\qquad(\mathbf{n}=\mathbf{3 7})\end{array}$ \\
\hline Median age at IBD diagnosis, years & \multicolumn{2}{|c|}{$32.5[27.3-42$} \\
\hline Male gender, no (\%) & \multicolumn{2}{|c|}{$24(25 \%)$} \\
\hline Body mass index, $\mathrm{kg} / \mathrm{m}^{2}$ & \multicolumn{2}{|c|}{$22.5 \pm 4.4$} \\
\hline Median duration of IBD, years & $2.3[6.7-17.3]$ & $7.7[5.3-12.9]$ \\
\hline \multicolumn{3}{|l|}{ Age at diagnosis - Montreal classification } \\
\hline A1 & \multicolumn{2}{|c|}{$14(15 \%)$} \\
\hline A2 & \multicolumn{2}{|c|}{$71(75 \%)$} \\
\hline $\mathbf{A 3}$ & \multicolumn{2}{|c|}{$10(10 \%)$} \\
\hline Median duration of vedolizumab therapy, & \multicolumn{2}{|c|}{$14.5[8.2-21.5]$} \\
\hline Current smoker, no (\%) & $19(33 \%)$ & $3(8 \%)$ \\
\hline $\begin{array}{l}\text { Clinical disease activity scoring at the time } \\
\text { of the last vedolizumab infusion }\end{array}$ & $\begin{array}{c}\text { Harvey-Bradshaw } \\
\text { Index } \\
1.7 \pm 1.4\end{array}$ & $\begin{array}{l}\text { Mayo Clinic score } \\
\qquad 1.3 \pm 1.7 \\
\text { Partial Mayo Clinic } \\
\text { score }\end{array}$ \\
\hline
\end{tabular}




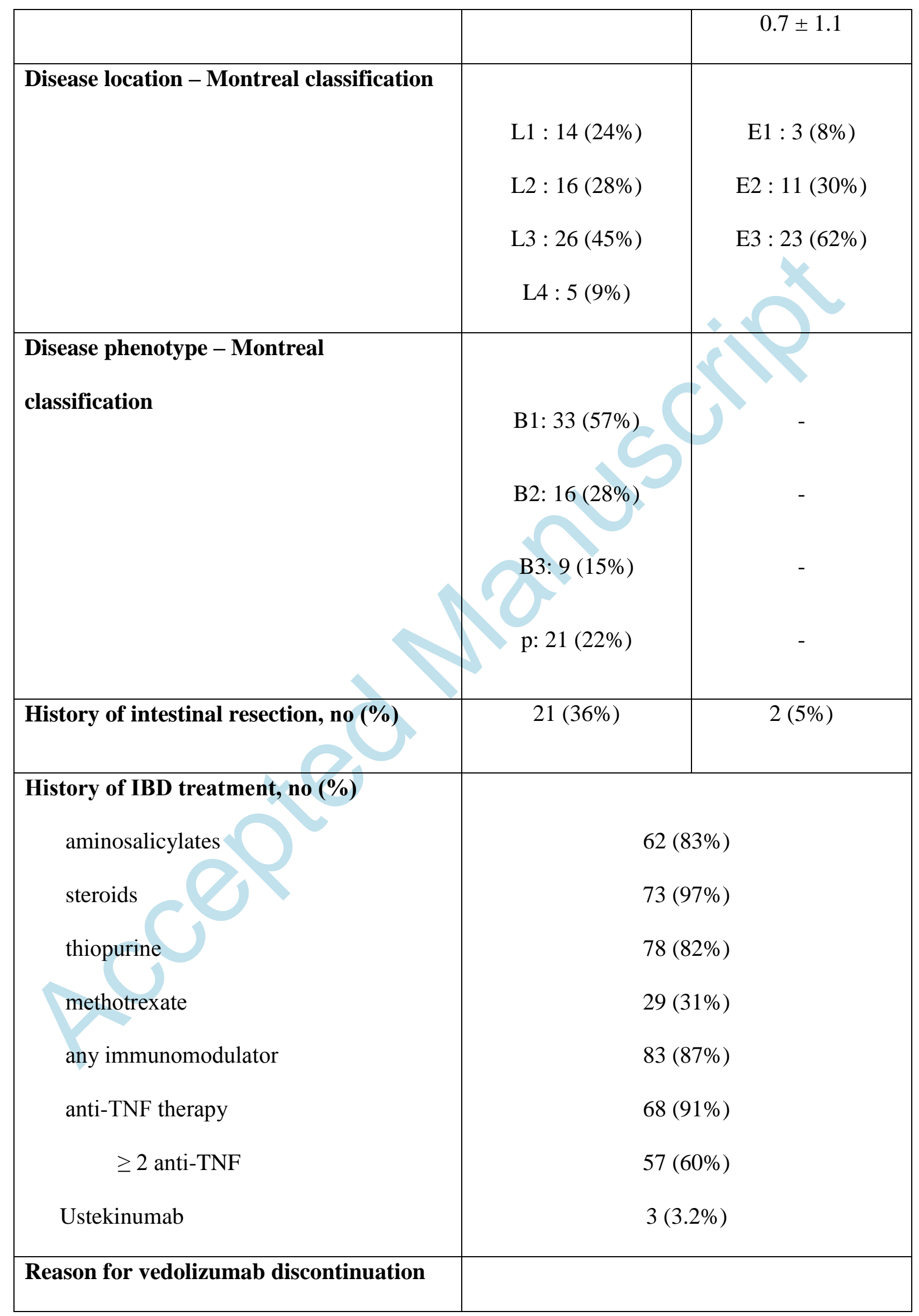




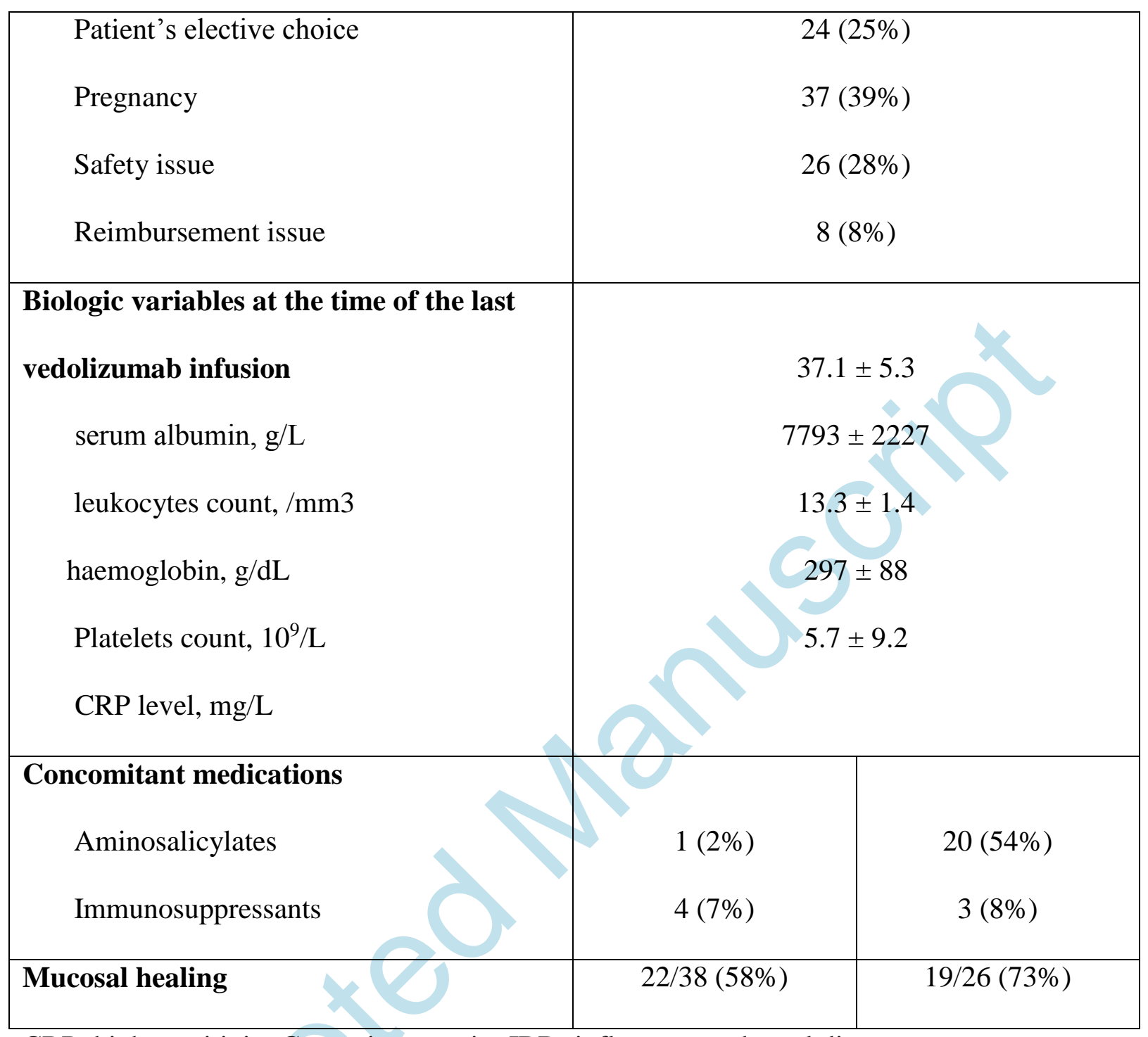

CRP: high sensitivity C-reactive protein; IBD: inflammatory bowel disease.

Variables are presented as $\mathrm{n}(\%)$, mean \pm standard deviation or median (interquartile range). 
Table 2: The predictors associated with clinical relapse after discontinuation of vedolizumab in 95 patients with inflammatory bowel disease in steroid-free clinical remission for at least three months, treated with vedolizumab therapy for at least six months.

\begin{tabular}{|c|c|c|c|c|}
\hline \multirow{3}{*}{ Risk factors } & \multicolumn{2}{|c|}{ Univariate analysis } & \multicolumn{2}{|c|}{ Multivariate analysis } \\
\hline & & & & $\mathrm{P}$ \\
\hline & HR (95\%CI) & $\mathrm{P}$ value & HR $(95 \% \mathrm{CI})$ & value \\
\hline CRP level at discontinuation $<5 \mathrm{mg} / \mathrm{L}$ & $\begin{array}{c}0.53[0.31- \\
0.90]\end{array}$ & 0.02 & $\begin{array}{l}0.56[0.33- \\
0.95]\end{array}$ & 0.03 \\
\hline Patient's elective decision & $\begin{array}{r}0.40[0.20 \\
0.76]\end{array}$ & 0.006 & $\begin{array}{c}0.41[0.21- \\
0.80]\end{array}$ & 0.009 \\
\hline HBI or partial Mayo Clinic score $\leq 1$ & $0.65[0.39-$ & 0.09 & - & NS \\
\hline Mucosal healing & $0.47[0.25-$ & 0.02 & - & NS \\
\hline Leukocytes count $>8000 / \mathrm{mm}^{3}$ & $\begin{array}{c}0.47[0.25- \\
0.90]\end{array}$ & 0.02 & - & NS \\
\hline $\begin{array}{l}\text { Concomitant steroids at the time of } \\
\text { vedolizumab introduction }\end{array}$ & $\begin{array}{c}2.08[1.22- \\
3.57]\end{array}$ & 0.007 & - & NS \\
\hline Reimbursement issue & $\begin{array}{c}4.35[2.04- \\
9.09]\end{array}$ & $<0.001$ & - & NS \\
\hline Crohn's disease & $\begin{array}{c}1.26(0.74- \\
2.14)\end{array}$ & 0.40 & - & NS \\
\hline
\end{tabular}


CRP: high sensitivity C-reactive protein; HBI: Harvey-Bradshaw Index; HR: hazard ratio; CI: confidence interval. Hazard ratio (HR) with $95 \%$ confidence interval (CI) was estimated using Cox models 
Manuscript Doi: 10.1093/ecco-jcc/jjaa005

Figure 1

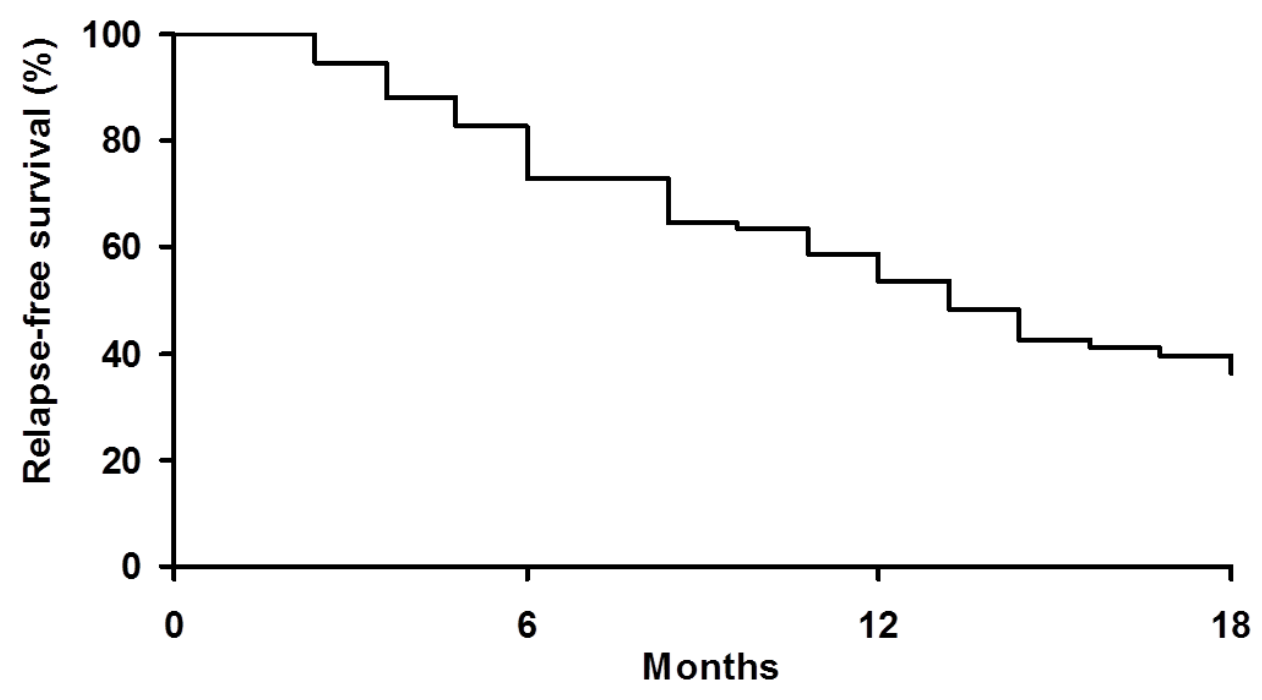

$\mathrm{N}$ at risk $\quad 95$

64

39

22 
Figure 2A

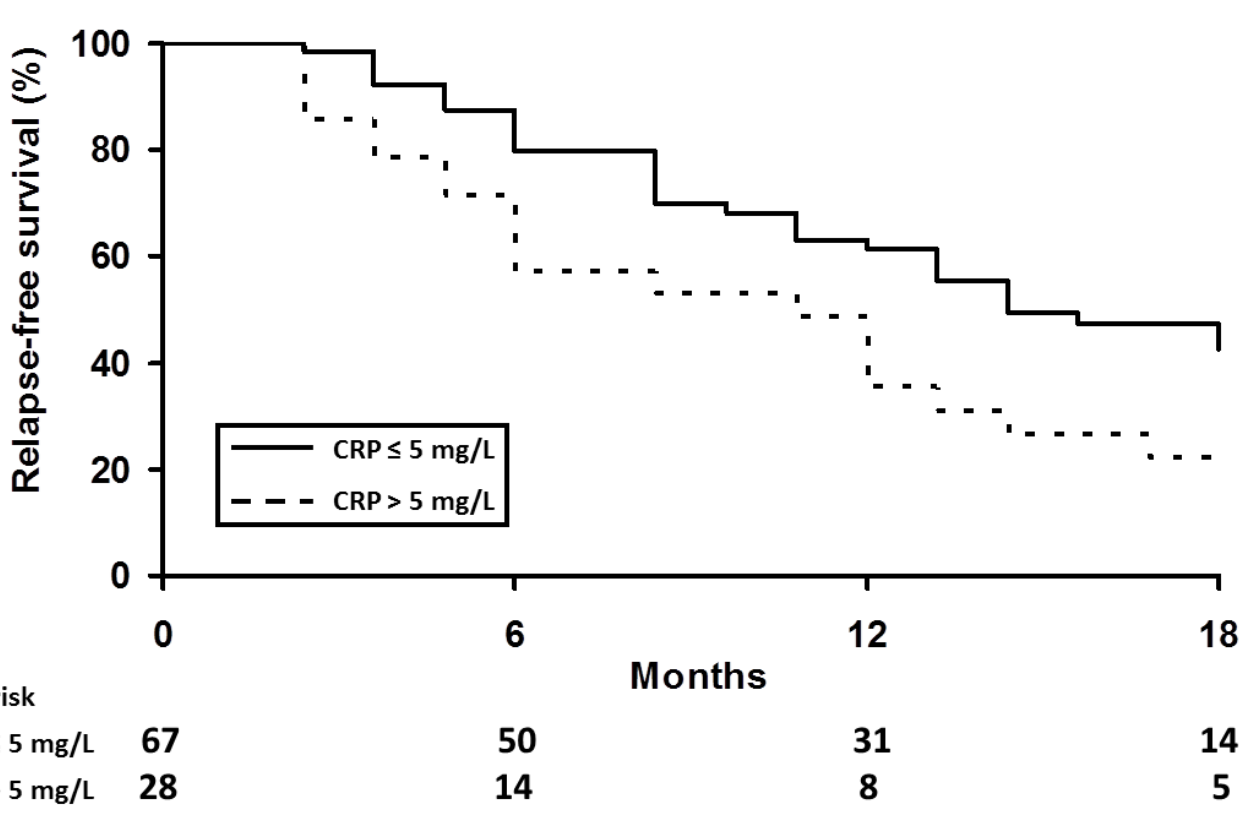

A 
Flgure 2B

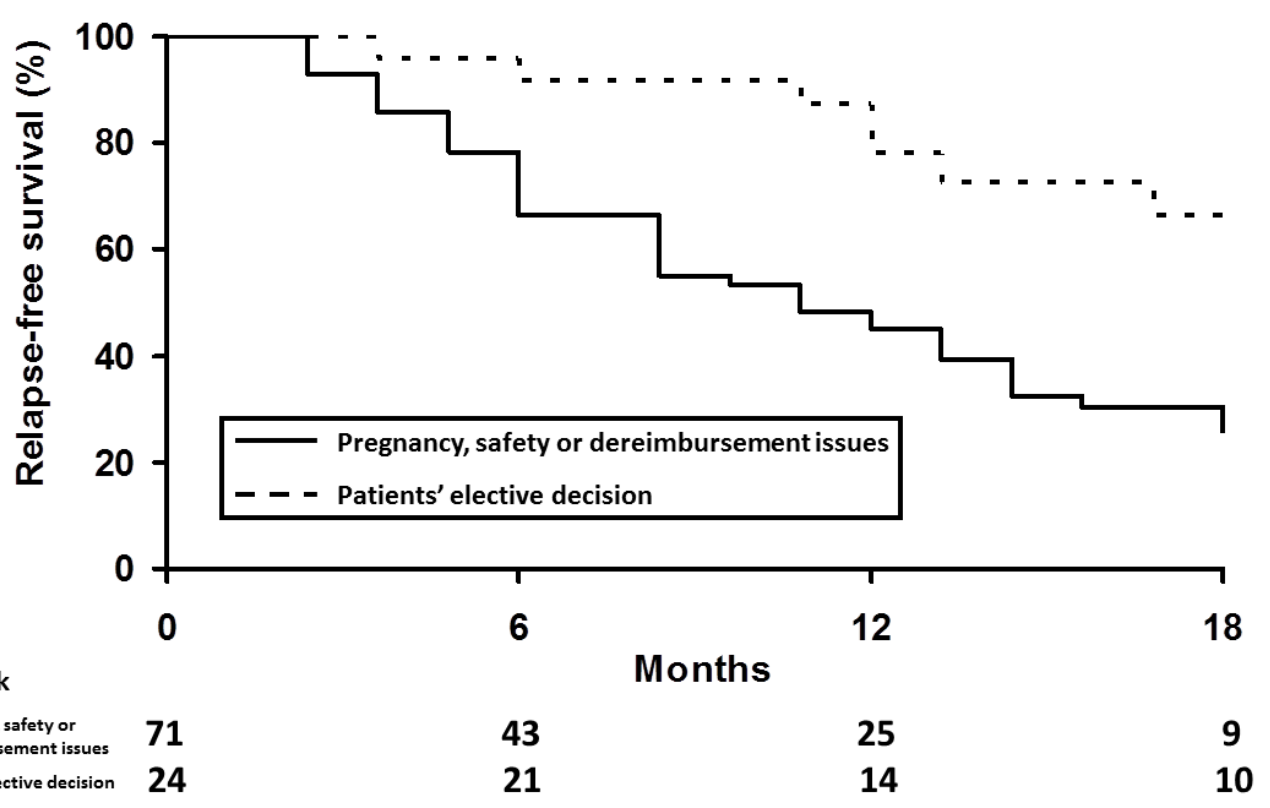


Figure 2C

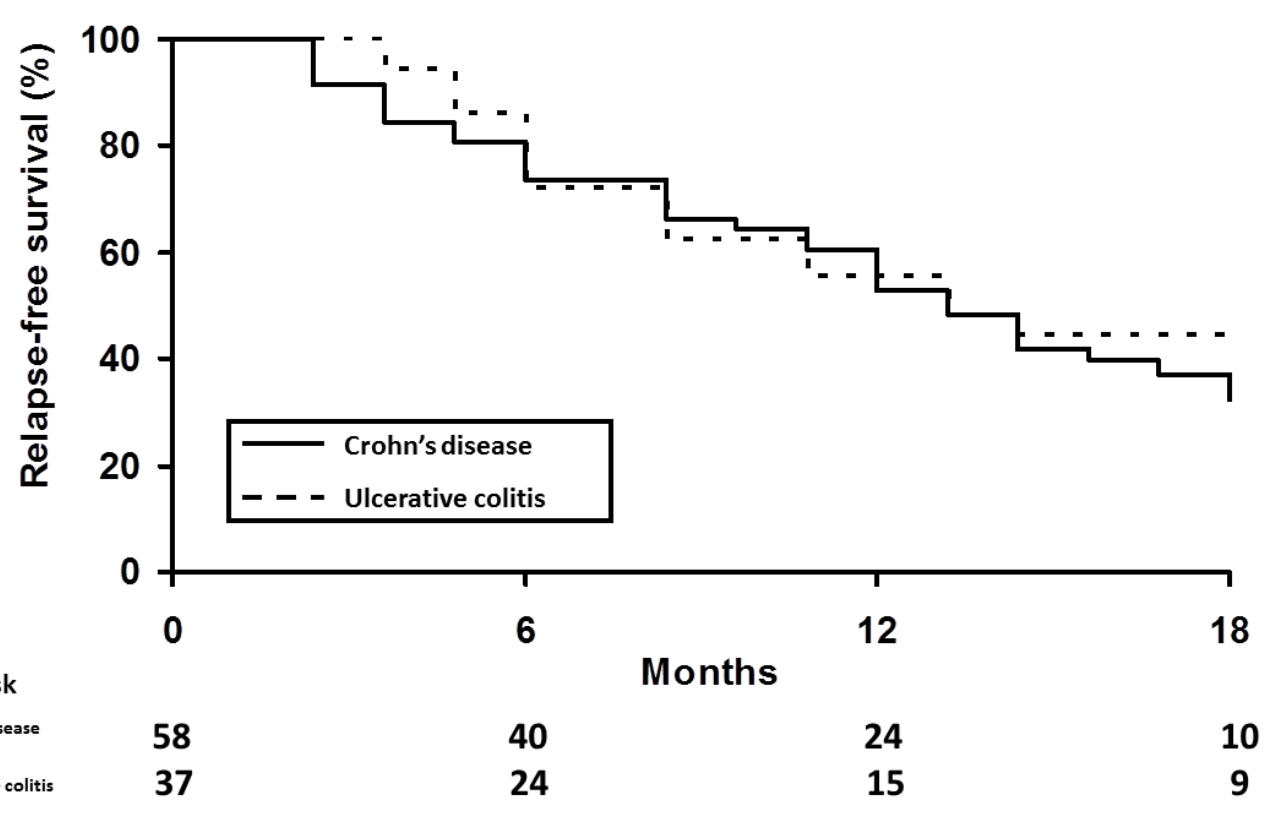

